J. Lake Sci. (湖泊科学) , 2015, 27(5): 819-828

DOI $10.18307 / 2015.0508$

(C) 2015 by Journal of Lake Sciences

\title{
稳定分层水库水质的季节性变化特征及扬水曝气水质改善"
}

\author{
巨 拓, 黄廷林**,马卫星, 周子振 \\ (西安建筑科技大学环境与市政工程学院,西安 710055)
}

\begin{abstract}
摘 要: 为了解深水型水库水体的热分层结构、水质特征及扬水曝气系统对水质的改善情况, 对水温、溶解氧、 $\mathrm{pH}$ 、 叶绿素 a、营养盐、溶解性有机碳浓度等水质指标进行为期一年的监测,探讨各项指标的季节性变化规律. 结果表明,黑河 水库水体呈单循环混合模式,在 3-10 月形成自然热分层,水体的热分层导致相应水库水质明显分层. 黑河水库为偏碱性 水体, 叶绿素 a、总磷、总氮、铵态氮和溶解性有机碳浓度平均值分别为 $2.21 \mu \mathrm{g} / \mathrm{L} 、 0.022 \mathrm{mg} / \mathrm{L} 、 1.32 \mathrm{mg} / \mathrm{L} 、 0.20 \mathrm{mg} / \mathrm{L}$ 和 $2.93 \mathrm{mg} / \mathrm{L}$, 表明黑河水库处于中-富营养状态. 热分层期底部水体溶解氧浓度在 $0 \sim 7.9 \mathrm{mg} / \mathrm{L}$ 之间, 平均值为 $2.9 \mathrm{mg} / \mathrm{L}$, 氮磷质量比在 $41 \sim 100$ 之间, 表明黑河水库是一个底部季节性缺氧、高营养盐型水库. 在水库自然热分层末期,应用扬水 曝气技术,不仅改善了底部水体的厌氧/缺氧环境,抑制了厌氧/缺氧条件下内源污染物的释放和藻类的增殖,而且还使 得水库水体提前混合, 实现了强制混合与水体自然混合过程的有机衔接, 延长了水质持续改善的作用时效,有效地改善 了水环境,保障了安全供水.
\end{abstract}

关键词: 深水型水库;热分层;扬水曝气; 提前混合; 水质改善;黑河水库

\section{Characteristics of seasonal variation and water-lifting aerator improvement of water quali- ty in a steady stratified reservoir}

JU Tuo, HUANG Tinglin, MA Weixing \& ZHOU Zizhen

(School of Environmental and Municipal Engineering, Xi'an University of Architecture and Technology, Xi'an 710055, P. R. China)

Abstract: In order to understand the thermal stratification, the characteristics of the water quality and the application of water-lifting aerator system in the deep reservoir, water temperature, dissolved oxygen, $\mathrm{pH}$, chlorophyll-a, nutrient and dissolved organic carbon(DOC) were monitored in a whole year. The results showed that Heihe Reservoir belonged to single hybrid mode, and the natural thermal stratification period was from March to October. The thermal stratification led water quality stratifications. The chlorophyll-a, total phosphorus, total nitrogen, ammonium nitrogen and DOC average concentrations were $2.21 \mu \mathrm{g} / \mathrm{L}, 0.022 \mathrm{mg} / \mathrm{L}$, $1.32 \mathrm{mg} / \mathrm{L}, 0.20 \mathrm{mg} / \mathrm{L}$ and $2.93 \mathrm{mg} / \mathrm{L}$, respectively, which showed that Heihe Reservoir was mesotrophic. In the thermal stratification period, the dissolved oxygen in the underlying water ranged from $0 \mathrm{mg} / \mathrm{L}$ to $7.9 \mathrm{mg} / \mathrm{L}$, with an average of $2.9 \mathrm{mg} / \mathrm{L}$, and the ratio of N/P was between 41 and 100, which showed that Heihe Reservoir had a seasonal hypoxia, with high nutrient concentrations. In the end of natural thermal stratification period, the application of water-lifting aerator technology can not only improve the bottom anaerobic/anoxic environment, and reduce the release of endogenous pollutants and the proliferation of algae, but also enhance the water mixture.

Keywords: Deep reservoir; thermal stratification; water-lifting aerator; mixed in advance; improvement of water quality; Heihe Reservoir

通常水库的建成会对其原有水质生态系统产生诸多影响 ${ }^{[1]}$, 改变天然河道的演变规律, 使水环境系统 出现类似于湖泊的“湖沼学反应” ${ }^{[2]}$,并引发河流水文情势、水生生态、水动力、地貌及水质等各方面的环境

* 国家自然科学基金项目 $(51478378,50830303)$ 资助. 2014-10-11 收稿;2015-02-05 收修改稿. 巨拓( 1988 ), 男,硕士研究生;E-mail:jutuo1988@163.com.

** 通信作者;E-mail:huangtinglin@ xauat. edu. cn. 
影响, 水体热分层现象就是其中较为突出的问题之一. 水体热分层泛指在同一水体中因冷、热水体密度差异 所导致的水体物理分层过程, 其主要表征为垂向水温梯度变化的不均匀. 学者们将水体稳定热分层时的结 构定义为典型的 “三层式” 水温分布模型 ${ }^{[3]}$, 即沿水深从上向下依次划分为温变层、温跃层和等温层.

随着热分层效应日渐突出, 水质周期性污染变得愈加严峻, 如何高效、合理、可持续地对水质进行改善 显得尤为重要, 水质原位修复技术作为一项重要的水质改善手段得以应用. 目前, 国外常用的水质原位修复 技术有: 同温层曝气技术 ${ }^{[4]}$ 、气泡混合技术 ${ }^{[5]}$ 和扬水筒混合技术 ${ }^{[6]}$. 其中, 同温层曝气技术 (亦称深水曝气技 术) 可直接对下层水体充氧, 但不能破坏水体分层结构. 国外对于深水䀧气应用较多, 且取得了良好的效果, 如德国 Wahnbach 水库 ${ }^{[7]}$ 、澳大利亚 Barossa 水库、美国 Prince 湖和 Western Branch 湖 ${ }^{[8]}$. 气泡混合技术具有 气泡与水接触面积大、直接充氧效率高等优点, 在荷兰 Nieuwe Meer 湖 ${ }^{[9]}$ 、英国 Hanning-field 水库 ${ }^{[10]}$ 都有应 用, 但混合能力相对有限, 在深水型湖库中应用难度很大. 扬水筒混合技术主要通过混合上、下水层破坏水 体分层结构, 但不具备直接充氧功能, 已被日本釜房水库、韩国 Daechung 湖 ${ }^{[11]}$ 等湖库采用. 国内应用较多的 是生物接触氧化法 ${ }^{[12]}$, 但其工艺复杂、投资较大. 本研究通过比较当前国内外水质原位修复技术, 结合黑河 水库实际水质污染现状与水文、水动力特性, 认为同时具有混合充氧、抑制底泥污染物释放和藻类生长等功 能的扬水曝气技术 ${ }^{[13-14]}$, 是有效改善黑河水库水质的首选工程措施.

黑河水库位于陕西省西安市周至县马召镇南黑河峪口以上约 $1.5 \mathrm{~km}$ 处, 距西安市 $86 \mathrm{~km}$, 最大水深为 $106 \mathrm{~m}$, 属深水型峡谷水库, 地处中温带, 具有典型的温带峡谷型水库的特征 ${ }^{[15-17]}$. 目前, 国内对热分层效应 与内源污染物释放、水环境质量特征及藻类迁移分布的相关性等方面的研究尚有不足, 现有研究多集中在 水温分布的预测模拟 ${ }^{[18-19]}$ 、简单物化因子的时空分布 ${ }^{[20]}$ 及对下游河道的水质影响方面 ${ }^{[21]}$. 如何有效降低内 源污染负荷和改善水库水质, 是水库目前面临的最大问题. 本研究以黑河水库为研究对象, 考察该水库目前 的水环境质量现状、水体热分层结构特征及热分层效应 ${ }^{[22-23]}$, 探讨扬水曝气系统对水库水质的可能影 响 ${ }^{[24-25]}$, 为水库水质的管理提供科学依据.

\section{1 材料与方法}

\section{1 黑河水库概况及水文特征}

1.1 .1 水库概况 黑河水库是一项以城市供水为主, 兼有农灌、发电、防洪等综合利用的大 (二) 型水利工 程. 枢纽由拦河坝、泄洪洞、溢洪洞、引水洞、坝后电站及古河道防渗工程等建筑物组成. 坝高 $130 \mathrm{~m}$, 坝顶高 程 $600 \mathrm{~m}$, 坝顶长度 $422 \mathrm{~m}$, 宽度 $11 \mathrm{~m}$, 坝址控制流域面积 $1481 \mathrm{~km}^{2}$, 最大库容 $2 \times 10^{8} \mathrm{~m}^{3}$, 有效库容 $1.77 \times$ $10^{8} \mathrm{~m}^{3}$, 主库区最大水域面积 $4.68 \mathrm{~km}^{2}$, 水面宽度 $240 \sim 680 \mathrm{~m}$, 库盆宽度 $50 \sim 200 \mathrm{~m}$, 平均水深 $70 \sim 90 \mathrm{~m}$, 最 大水深 $106 \mathrm{~m}$, 库底最小高程 $488.5 \mathrm{~m}$. 正常高水位 $594.0 \mathrm{~m}$, 汛限水位 $593.0 \mathrm{~m}$, 每年向西安市供水 $3.05 \times 10^{8} \mathrm{~m}^{3}$, 日平均供水量为 $76.0 \times 10^{4} \mathrm{~m}^{3}$, 是目前西安市引水工程的主要水源, 其水质的优劣直接影响 着西安市民的用水安全.

1.1 .2 水库水文特征 2013 年 3 月一 2014 年 2 月期间,水库最低水位出现在 2013 年 5 月 3 日,为 $545.2 \mathrm{~m}$ (黄海高程); 最高水位出现在 2013 年 7 月 28 日, 为 $591.18 \mathrm{~m}$; 水库区域平均面降雨量在 $0.3 \sim 244 \mathrm{~mm}$ 之 间, 降雨量最大值出现在 7 月, 最小值出现在 12 月; 丰水期水位较高, 枯水期水位相对较低; 日平均人库流量 在 2013 年 12 月最低, 为 $2.7 \mathrm{~m}^{3} / \mathrm{s}$; 最大值出现在 2013 年 7 月, 为 $460 \mathrm{~m}^{3} / \mathrm{s}$. 黑河水库每月的人库流量与降 雨量具有相似的趋势. 需要说明的是, 汗期降雨多为暴雨, 且持续时间长, 致使流域内暴雨径流量急剧增大, 冲刷大量泥沙、腐殖质等污染物进人水库,造成水质短期内的恶化.

\section{2 扬水曝气器介绍}

为控制热分层期底部水体中溶解氧 (DO) 的过度消耗所导致的水质恶化, 需采取有效措施促进底部水 体中 DO 的更新. 最为直接的方法就是在热分层期采用适当方法增加水体中的 DO, 延迟热分层的形成或缩 短分层期的持续时间, 减缓其对底部水体中 DO 的消耗. 扬水曝气技术是一种直接且有效的方法, 其通过扬 水曝气器以压缩空气为动力, 压缩空气连续地通人环形空气释放管, 由管道微孔向曝气室释放气泡, 从而向 水体充氧. 充氧水流从回流室返回到下层水体, 充氧后的尾气收集在气室中. 当气体充满气室后, 瞬间向上 升筒释放并形成大的气弹. 气弹迅速上浮, 形成了上升的活塞流, 推动上升筒中的水体加速上升, 直至气弹 
冲出上升筒出口. 随后, 上升筒中的水流在惯性 作用下继续上升, 直至下一个气弹形成. 上升筒 不断从下端吸人水体输送到表层, 被提升的底层 水与表层水混合后向四周扩散,形成了上、下水 层间的循环混合, 不仅增加了水体 DO 浓度, 而且 提升了垂向水体的流动性和交换性, 扰乱了水体 的密度层, 破坏了水体分层结构. 黑河水库扬水 曝气器是结合水库实际蓄水状况与水动力特性, 在原普通淹没式扬水曝气器的基础上改进而来, 布置于黑河水库大坝前 $1.1 \mathrm{~km}$ 范围内, 共 8 台, 间距 $250 \sim 300 \mathrm{~m}$, 呈梅花形分布(图 1).

\section{3 水样采集点}

1.3.1 主库区水样采集点 结合主库区地形和径 流特点, 在黑河水库主库区设置 S1、S2、S3、S4 4 个采样点 (图 1), 其中前 3 个采样点分别位于水 库不同水深处的原河道主流区, S4 样点正对于泄 洪塔附近. 这 4 个点既能反映主库区不同地点、不 同深度水质的变化情况, 又能反映暴雨径流对主 库区水质的影响. S1 点位正对饮水塔附近, 进行 逐月多次采样, 每个采样点在上部 (水下 $0.5 \mathrm{~m}$ )、 底部 (底泥上 $0.5 \mathrm{~m}$ ) 及水深每隔 $10 \mathrm{~m}$ 处取样, 采 用有机玻璃垂向直立式采样器. 水位和人库流量 等数据由水库管理站提供.

1.3 .2 水库上游水样采集点 黑河流域森林茂 密、植被丰富, 具有良好的水源涵养作用, 且上游 沿线地区无工矿企业及工业污染; 村镇散落, 居 民较少, 排放的生活污水较少. 根据黑河水库上 游河道水力特点, 在水流平缓、冲刷作用较弱的 地方选取 7 个代表性断面, 每个断面的采样点设 置在中弘线上 (图 2).

\section{4 数据处理方法与样品分析方法}

主库区水质研究采用正对于饮水塔附近的 $\mathrm{S} 1$ 点的数据, 并对上游 7 个采样点 $(\mathrm{CS} 3 \sim \mathrm{CS} 9)$ 的数据进行分析, 研究其对主库区水质变化的影 响. 数据处理如下: (1) 将每月多次采集水样的水 质数据取平均值, 作为本月的水质数据; (2) 将各 月各指标的数据采用 SPSS 软件进行统计分析.

水质监测时间为 2013 年 3 月- 2014 月 2 月, 水深、水温、DO、 $\mathrm{pH}$ 、叶绿素 $\mathrm{a}(\mathrm{Chl} . \mathrm{a})$ 浓度等采用 美国哈希公司多功能水质监测仪 Hydrolab DS5 现场原位在线测定, 其原理与参数见表 1 , 总磷 $(\mathrm{TP})$ 、总氮 $(\mathrm{TN})$ 、铵态氮 $\left(\mathrm{NH}_{4}^{+}-\mathrm{N}\right)$ 、溶解性有机 碳 $(\mathrm{DOC}) 、$ 、铁 $(\mathrm{Fe})$ 浓度等水质指标均参照《水和 废水监测分析方法》 (第 4 版 ${ }^{[26]}$ 进行测定, 其中

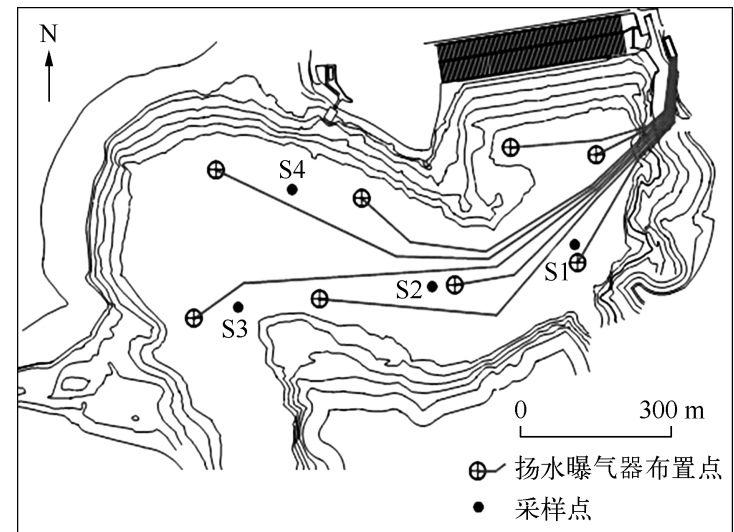

图 1 黑河水库主库区采样点及扬水曝气器布置点

Fig. 1 The sampling sites and layout of water-lifting aerators in Heihe Reservoir

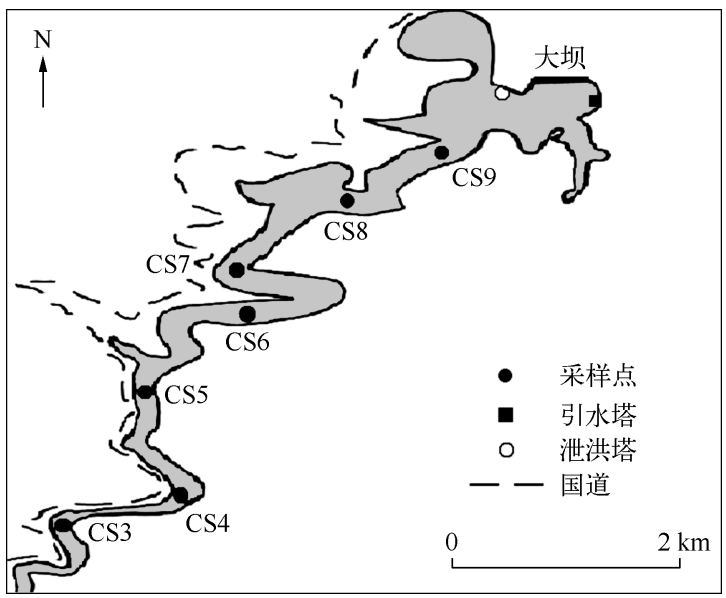

图 2 黑河水库上游采样点

Fig. 2 The sampling sites in the upstream of Heihe Reservoir

表 1 多功能水质监测仪 Hydrolab DS5 的监测原理与探头传感器参数

Tab. 1 Multifunctional water quality monitor Hydrolab DS5 monitoring principle and the probe sensor parameters

\begin{tabular}{ccc}
\hline 监测指标 & 检测原理 & 量程/精度/分辨率 \\
\hline 水深 $/ \mathrm{m}$ & 压敏电阻法 & $0 \sim 100 / \pm 0.05 / 0.01$ \\
水温 $/{ }^{\circ} \mathrm{C}$ & 热敏电阻法 & $-5 \sim 50 / \pm 0.1 / 0.01$ \\
$\mathrm{DO} /(\mathrm{mg} / \mathrm{L})$ & $\mathrm{CLARK}$ 膜电极法 & $0 \sim 50 / \pm 0.2 / 0.01$ \\
$\mathrm{pH}$ 值 & 玻璃电极法 & $0 \sim 14 / \pm 0.2 / 0.01$ \\
$\mathrm{Chl} . \mathrm{a} /(\mu \mathrm{g} / \mathrm{L})$ & 体内苂光法 & $0 \sim 50 / \pm 3 \% / 0.01$ \\
\hline
\end{tabular}


$\mathrm{TP}$ 浓度用钿锑钪分光光度法测定, $\mathrm{TN}$ 浓度用碱性过硫酸钾消解- 紫外分光光度法测定. $\mathrm{NH}_{4}^{+}-\mathrm{N}$ 浓度用纳氏 试剂比色法测定, DOC 浓度用燃烧氧化-非分散红外吸收法测定, Fe 浓度用邻菲罗啉分光光度法测定.

\section{2 结果与讨论}

\section{1 水温的季节变化与垂直分层}

随着 4 月份气温的回升, 黑河水库表层水温升高, 密度减小, 而底部水温仍然维持在原有状态, 密度较 大, 上、底部水体密度存在显著差异, 导致水库形成热分层, 从而阻碍了上、底部水体间的物质混合交换 ${ }^{[27]}$. 黑河水库属深水型水库, $30 \mathrm{~m}$ 以上水温年际变化较大, 上部水温全年在 $6.4 \sim 25.9^{\circ} \mathrm{C}$ 范围内变化, 底部水温 则变幅较小(图 3). 3-10 月热分层期,黑河水库水温保持 “上高下低” 的分层结构, 上、底部温差在 2.6 $14.3^{\circ} \mathrm{C}$ 之间, 8 月份水体分层最稳定,形成了深度为 $20 \mathrm{~m}$ 、温差为 $14.3^{\circ} \mathrm{C}$ 的温跃层 ${ }^{[28]} ; 9$ 月份后, 由于扬水曝 气系统的提水混合作用, 使得水库水体提前开始混合, 上、底部水体温差逐渐减小; 至 10 月末, 整个水体完 全混合, 温跃层消失, 混合后水温也提高至 $17^{\circ} \mathrm{C}$ 左右. 黑河水库水体全年呈现单循环混合模式, 显然这种分 层结构与亚热带水库分层具有相似性, 同时区别于其他地区的双混合型或全年稳定分层的水库 ${ }^{[29]}$.

\section{$2.2 \mathrm{DO}$ 浓度的季节变化与垂直分层}

黑河水库水体 DO 浓度大小取决于复氧与耗氧过程的相对强弱, 同时受水温、水质、水动力及氧分压等 环境因素的综合影响 ${ }^{[30]}$. 热分层期,DO 浓度沿水深整体呈 “上高下低” 的趋势分布 (图 3), 这是由于表层水 体在大气复氧和藻类光合作用的双重作用下, DO 浓度接近当地气候件下的饱和 DO 浓度. 随着水深的增加 及温度梯度的存在, 氧传质及光合产氧作用逐渐降低, 而水体又不断耗氧, DO 浓度随之降低; 越接近水库底 部, 氧传质过程越受阻, 加之水体及沉积物中有机质矿化降解不断耗氧, DO 浓度越低, 使库底出现缺氧或戻 氧环境. 黑河水库扬水曝气系统运行后, 底部水体 DO 浓度明显提高.

\section{$2.3 \mathrm{pH}$ 值的季节变化与垂直分层}

黑河水库为偏碱性水体 (图 3). 热分层期, 上部水体 $\mathrm{pH}$ 值在 $7.4 \sim 9.2$ 之间, 均值为 8.4 ; 中部水体 $\mathrm{pH}$ 值在7. $3 \sim 8.4$ 之间, 均值为 7.9; 底部水体 $\mathrm{pH}$ 值在 $7.1 \sim 7.7$ 之间, 均值为 7.4. 上、中、底部水体 $\mathrm{pH}$ 值差异 较大 $(P<0.01)$, 其中 8 月最为显著, 这是由于这一时期藻类光合作用较强, 大量消耗水中的 $\mathrm{CO}_{2}$, 对水环境 中的碳酸盐动态平衡体系 $\left(\mathrm{CO}_{3}^{2-} / \mathrm{HCO}_{3}^{-} / \mathrm{CO}_{2}\right)$ 产生扰动, 促使上部水体 $\mathrm{pH}$ 值升高并呈微碱性. 随着水深增 加, 光照强度衰减, 藻类丰度急剧下降, DO 浓度不断降低, 兼性戻氧菌逐渐变得活跃, 它们在自身的新陈代 谢及对水中有机质矿化降解的过程中, 不断产生并积累 $\mathrm{CO}_{2}$, 致使底部水体 $\mathrm{pH}$ 值降低. 在混合期, 上、中、底 部水体 $\mathrm{pH}$ 值总体差异不大 $(P>0.05)$. 可见, 黑河水库 $\mathrm{pH}$ 值亦具有季节性的分层特征, 其变化与同时期水 温、DO 浓度变化趋势基本一致, 总体上随水深的增加而减小; 水库周期性分层与混合对水体酸碱度体系存 在重要影响; $\mathrm{pH}$ 值降低也会加快沉积物的释放,对水质产生影响.

\section{$2.4 \mathrm{Chl} . \mathrm{a}$ 浓度的季节变化与垂直分层}

水体中的 Chl. a 浓度水平在一定程度上反映了水中藻类数量, 并且与藻类的生长活动、水体透明度、营 养盐水平以及其自身悬浮特征有着密切关系 ${ }^{[31]}$. 在连续一年的监测中, 黑河水库上部水体 Chl. a 浓度在 $0.35 \sim 7.09 \mu \mathrm{g} / \mathrm{L}$ 之间, 最低值出现在 3 月, 最高值出现在 8 月, 整体处于较高水平, 而中部和底部水体Chl. a 浓度则较低. 5-8 月, 上部水体 Chl. a 浓度都处在 $5 \mu \mathrm{g} / \mathrm{L}$ 以上, 丰水期其浓度明显高于枯水期 (图 3), 表明 5-8 月黑河水库水体处于富营养状态. 热分层期, 上、中、底部水体 Chl. a 浓度差异极显著 $(P<0.01)$, 而混 合期则差异不大 $(P>0.05)$, 在混合期, 氮、磷营养盐浓度较高, 但 Chl. a 浓度却处于较低水平, 可能受这一 时期水温较低的影响.

\section{5 水体氮、磷、有机物浓度及浊度的季节变化与垂直分层}

2013 年 3 月一 2014 年 2 月, 黑河水库上部水体 TP 浓度变幅为 $0.004 \sim 0.032 \mathrm{mg} / \mathrm{L}$, 年均值为 $0.014 \mathrm{mg} / \mathrm{L}$; 中部水体 TP 浓度变幅为 $0.005 \sim 0.034 \mathrm{mg} / \mathrm{L}$, 年均值为 $0.020 \mathrm{mg} / \mathrm{L}$; 底部水体 $\mathrm{TP}$ 浓度变幅为 $0.008 \sim$ $0.052 \mathrm{mg} / \mathrm{L}$, 年均值为 $0.031 \mathrm{mg} / \mathrm{L}$ (图 4). 总体上, 黑河水库 TP 浓度处于较低水平. 热分层期, 底部水体 $\mathrm{TP}$ 浓度在 3 月份最低, 为 $0.008 \mathrm{mg} / \mathrm{L}$; 但随着库底季节性缺氧的出现, 沉积物附近氧化还原电位降低, 不同形 态的磷不断转化释放进人上覆水中, 使得底部水体 TP 浓度迅速增大, 极大值出现在 5 月和 7 月, 分别为 

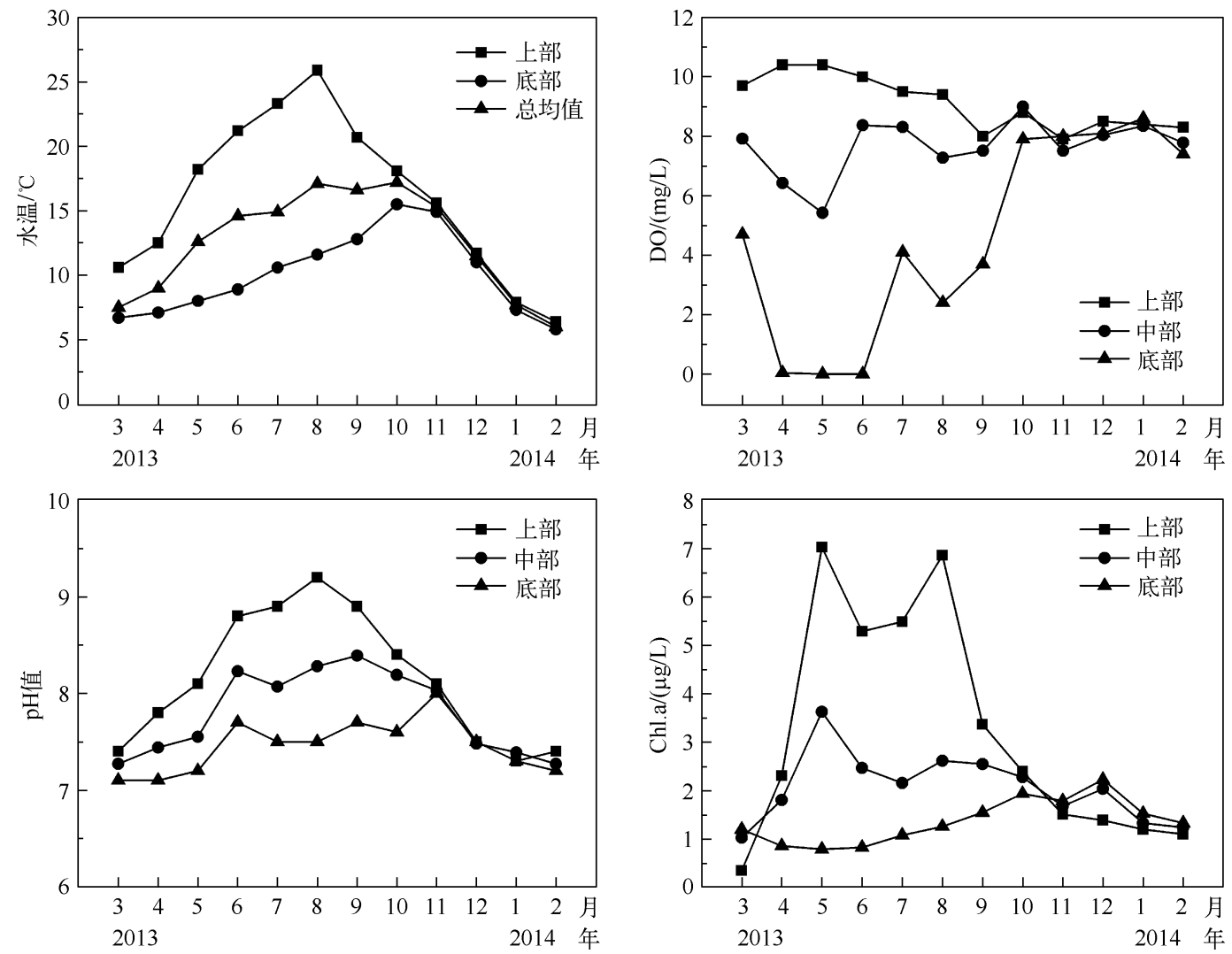

图 3 黑河水库 $\mathrm{S} 1$ 点位水温、DO、pH 值和 Chl. a 浓度的时空分布

Fig. 3 Spatial and temporal distribution of water temperature, DO, pH and chlorophyll-a concentration in the water column of S1 site of Heihe Reservoir

0.050 和 $0.052 \mathrm{mg} / \mathrm{L}$. 水体混合后底部水体 DO 浓度增加, 磷释放受到抑制.

热分层期, 黑河水库上、中、底部水体 $\mathrm{TN}$ 浓度分别为 $1.28 、 1.33 、 1.35 \mathrm{mg} / \mathrm{L}, \mathrm{NH}_{4}^{+}-\mathrm{N}$ 浓度分别为 0.14 、 $0.23 、 0.26 \mathrm{mg} / \mathrm{L}$; 混合期, 上、中、底部水体 $\mathrm{TN}$ 浓度分别为 $1.37 、 1.30 、 1.28 \mathrm{mg} / \mathrm{L}, \mathrm{NH}_{4}^{+}-\mathrm{N}$ 浓度分别为 0.20 、 $0.18 、 0.20 \mathrm{mg} / \mathrm{L}$. 显然, 热分层期上部水体 $\mathrm{TN} 、 \mathrm{NH}_{4}^{+}-\mathrm{N}$ 浓度比混合期低(图 4 ), 表明在厌氧状态下底泥中的 氮开始向上覆水体中释放, 分层则阻隔了其与上部水体之间的交换. 总体来看, 黑河水库目前的氮污染水平较 高, $\mathrm{TN}$ 浓度在 6 月达到最大值, 接近 $2 \mathrm{mg} / \mathrm{L}$. 而降雨量最大的 $7 、 8$ 月, $\mathrm{NH}_{4}^{+}-\mathrm{N}$ 浓度高出年平均值 2 倍多. 主要 原因为:一方面, 强降雨导致水库 $\mathrm{NH}_{4}^{+}-\mathrm{N}$ 浓度升高; 另一方面, 上游水携带的腐殖质以及上游居民生活污染物 进人库区, 其中的有机氮在有利的好氧环境下经氨化菌转化为 $\mathrm{NH}_{4}^{+}-\mathrm{N}$, 从而使水库 $\mathrm{NH}_{4}^{+}-\mathrm{N}$ 浓度升高.

2013 年 3 月- 2014 年 2 月, 黑河水库上部水体 DOC 浓度变幅为 $1.91 \sim 4.73 \mathrm{mg} / \mathrm{L}$, 年均值为 $3.18 \mathrm{mg} / \mathrm{L}$; 中部水体 DOC 浓度变幅为 $1.37 \sim 3.94 \mathrm{mg} / \mathrm{L}$, 年均值为 $2.75 \mathrm{mg} / \mathrm{L}$; 底部水体 DOC 浓度变幅为 $1.68 \sim$ $4.04 \mathrm{mg} / \mathrm{L}$, 年均值为 $2.85 \mathrm{mg} / \mathrm{L}$ (图 4). 水体 DOC 浓度变化的主要原因为: (1) 厌氧条件下有机氮及有机质的 分解伴随着 DOC 的释放,使得水体中 DOC 浓度增高; 2 沉积物中释放的 DOC 被其中的微生物分解利用. 在 热分层期, 底部水体出现缺氧, 特别是 4-6月, 底部水体 DO 浓度为 $0 \mathrm{mg} / \mathrm{L}$, 处于完全厌氧状态, 有机氮及有机 质大量分解、释放, 进人上覆水中; 混合初期, 底部水体高浓度的 DOC 被携带进人中、上部水体, 使中、上部水体 DOC 浓度增大. 而随着混合期全库的好氧, 沉积物中释放的 DOC 不断被微生物分解, 分解速度超过了释放速 度, 主要原因是在好氧状态下 $\mathrm{NH}_{4}^{+}-\mathrm{N}$ 释放量较少, 伴随 $\mathrm{NH}_{4}^{+}-\mathrm{N}$ 释放的 $\mathrm{DOC}$ 也较少, 且释放出的有机物在好氧 状态下很快被微生物分解利用, 所以其 DOC 浓度一直处于较低的水平. 

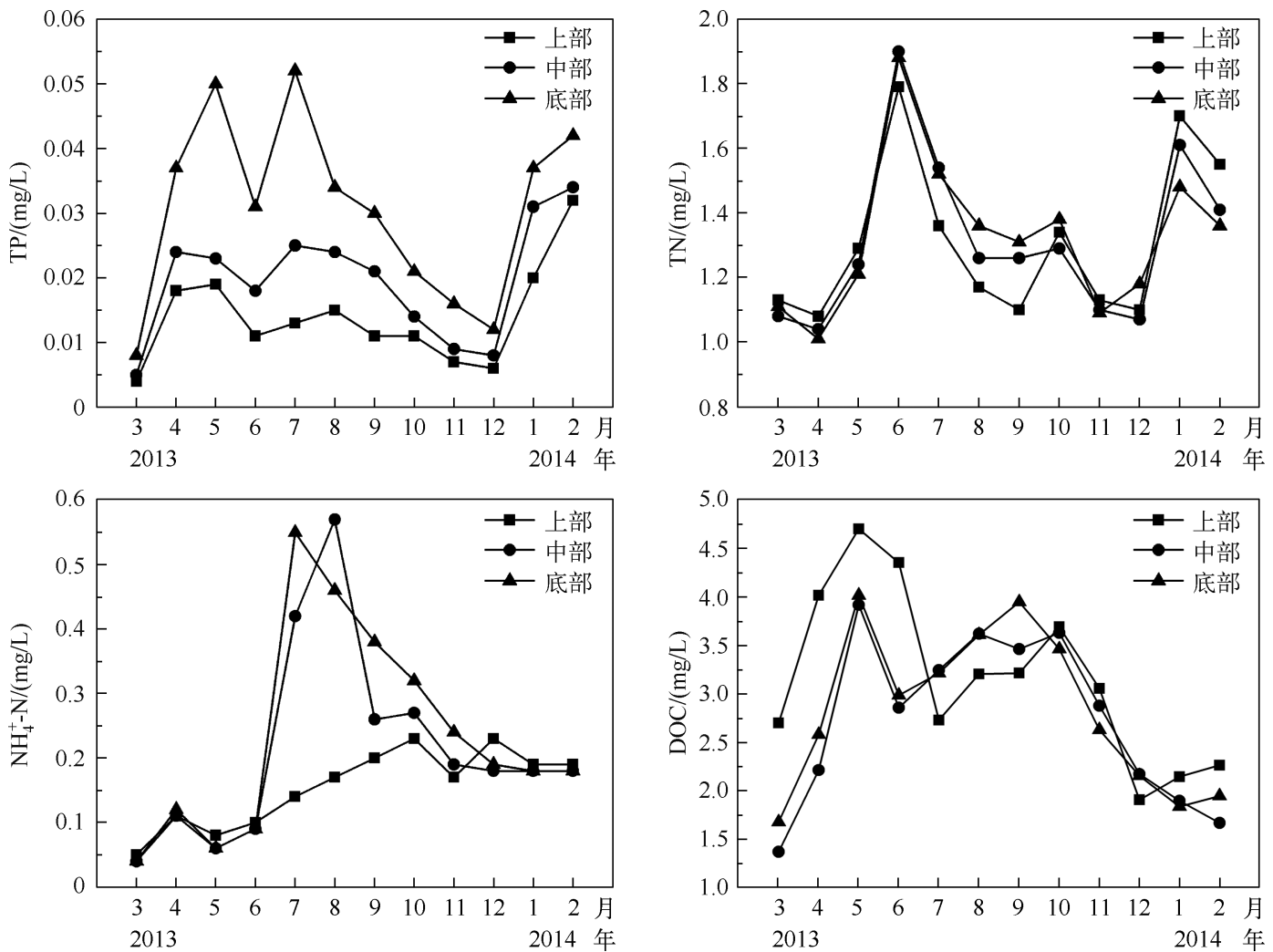

图 4 黑河水库 $\mathrm{S} 1$ 点位水体 $\mathrm{TP} 、 \mathrm{TN} 、 \mathrm{NH}_{4}^{+}-\mathrm{N}$ 和 $\mathrm{DOC}$ 浓度的时空分布

Fig. 4 Spatial and temporal distribution of TP, TN, $\mathrm{NH}_{4}^{+}-\mathrm{N}$ and DOC concentrations in the water column of S1 site of Heihe Reservoir

降雨期间, 雨水及上游水体的 $\mathrm{TN} 、 \mathrm{NH}_{4}^{+}-\mathrm{N}$ 浓度都较高; 上游水人库, 对主库区水体氮、磷营养盐及有机 物影响较大 (表 2), 表明暴雨径流对主库区水体的污染不容忽视. 在注重内源污染的同时应及时做好外源水 营养盐及有机物输人的控制. 降雨也导致上游水浊度大幅增大, 并以径流的方式潜人到主库区, 7 月 26 日和 30 日主库区的水体浊度 $(93 、 77.3 \mathrm{NTU}$ ) 分别比 7 月 23 日增加了 $50 \%$ 和 $24 \%$.

表 22013 年 7 月 23 日黑河水库上游水、雨水与主库区水质对比

Tab. 2 The comparison of water quality among upstream, rainwater and the pelagic zone of Heihe Reservoir on July 23th, 2013

\begin{tabular}{cccccccc}
\hline 指标 & CS3 点位 & CS5 点位 & CS6 点位 & CS7 点位 & CS9 点位 & S1 点位 & 雨水 \\
\hline $\mathrm{TN} /(\mathrm{mg} / \mathrm{L})$ & 1.35 & 1.36 & 1.36 & 1.37 & 1.39 & 1.44 & 1.22 \\
$\mathrm{NO}_{3}^{-}-\mathrm{N} /(\mathrm{mg} / \mathrm{L})$ & 0.88 & 0.79 & 0.70 & 0.48 & 0.66 & 1.09 & 0.53 \\
$\mathrm{NH}_{4}^{+}-\mathrm{N} /(\mathrm{mg} / \mathrm{L})$ & 0.44 & 0.54 & 0.64 & 0.86 & 0.71 & 0.33 & 0.66 \\
$\mathrm{TP} /(\mathrm{mg} / \mathrm{L})$ & 0.029 & 0.040 & 0.060 & 0.063 & 0.058 & 0.031 & 0.014 \\
$\mathrm{COD} /(\mathrm{mg} / \mathrm{L})$ & 4.5 & 4.1 & 4.1 & 4.5 & 4.5 & 4.1 & 3.7 \\
浊度 $/ \mathrm{NTU}$ & 102.8 & 120.3 & 188.7 & 232.9 & 229.3 & 62.4 & - \\
\hline
\end{tabular}

\section{6 扬水曝气技术对水体热分层结构及 DO 浓度的影响}

2.6.1 混合效果 水温是反映扬水曝气器混合效果的重要指标之一. 通过水温变化可以反映黑河水库扬水 曝气器的混合效果 (图 5). 扬水曝气系统运行前水体保持稳定的分层结构, 上、下层水温差约为 $12^{\circ} \mathrm{C}$. 随着 
扬水曝气系统的持续运行,垂向热分层结构产生了较大程度的扰动,一方面降低了表层水体温度,另一方面 迫使温跃层位置不断下迁, 范围压缩, 温差减小, 等温层范围不断缩小, 温变层范围不断扩大, 且上、下层水 体逐渐趋于均温化,水体混合效果显著.

2.6.2 充氧效果 扬水曝气系统开始运行前, 底部水体 DO 浓度已降至 $0.1 \mathrm{mg} / \mathrm{L}, \mathrm{DO}$ 浓度上高下低的分布 趋势很显著; 运行至第 $15 \mathrm{~d}$, 底部水体 DO 浓度就已回升至 $6.0 \mathrm{mg} / \mathrm{L}$ 以上 (图 5); 随着扬水曝气系统的持续 运行, DO 浓度沿水深的垂向梯度大大减小, 滞水层 DO 浓度大幅度提高, 两者存在正相关性 $(r=0.591$, $\left.Y_{\mathrm{DO}}=5.454+0.147 X_{\text {运行时间 }}\right)$; 运行末期, 滞水层 DO 平均浓度较运行前升高了 1.5 倍, 且上、下层水体 DO 浓 度基本趋于一致. 水体充氧效果显著 $(P<0.01)$.
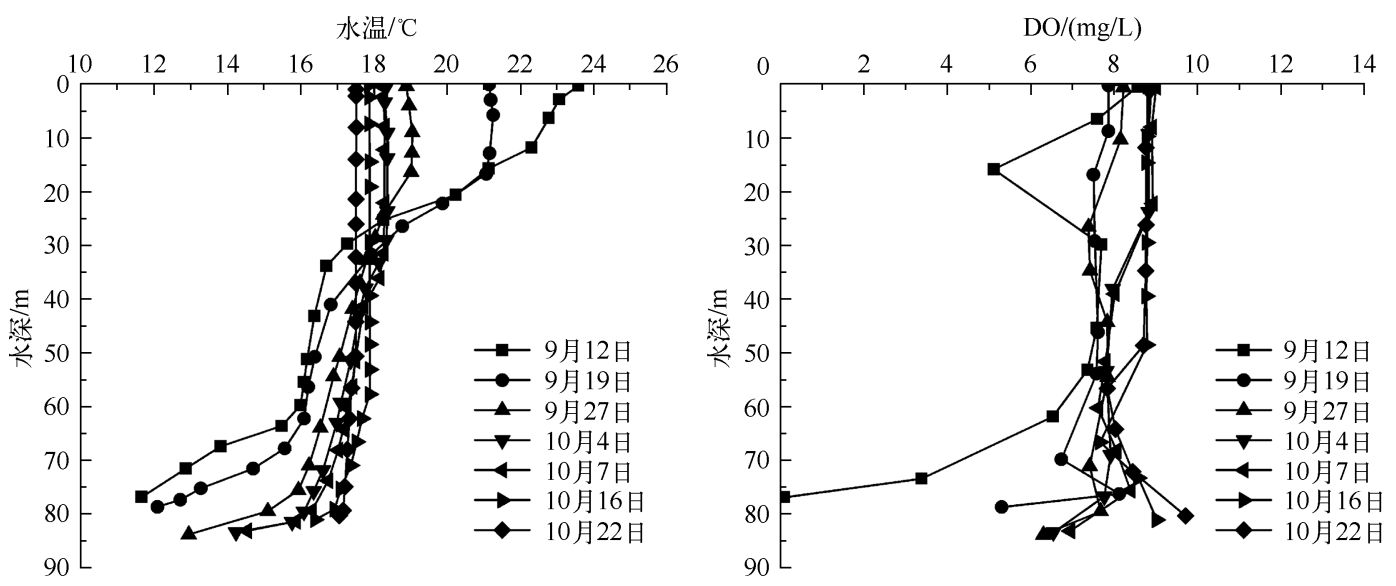

图 5 黑河水库 $\mathrm{S} 1$ 点位水体温度和 $\mathrm{DO}$ 浓度的垂向分布

Fig. 5 The vertical distribution of water temperature and DO concentration in the water column of S1 site of Heihe Reservoir

\section{7 扬水曝气技术对水质改善效果的影响}

2.7 .1 对沉积物中污染物释放的抑制 夏、秋季, 黑河水库底部水体 DO 浓度通常会降至 $2 \mathrm{mg} / \mathrm{L}$ 以下, 使沉 积物中氮、磷、铁、锰等污染物大量释放并向上覆水体中扩散, 导致水库水质季节性污染. 提高水体中 DO 浓 度可以有效地控制底泥中污染物的释放.

扬水曝气系统运行前, 黑河水库底部水体 TP 浓度为 $0.042 \mathrm{mg} / \mathrm{L}$; 随着扬水曝气系统的持续运行, 中、下 部水体 TP 浓度逐渐降低; 运行至第 $25 \mathrm{~d}$, 底部水体 $\mathrm{TP}$ 浓度降至 $0.023 \mathrm{mg} / \mathrm{L}$, 垂向水体 $\mathrm{TP}$ 平均浓度为 $0.016 \mathrm{mg} / \mathrm{L}$; 运行 $40 \mathrm{~d}$ 后, 水体已完全混合, 底部和垂向水体 TP 浓度趋于一致,维持在 $0.010 \mathrm{mg} / \mathrm{L}$ 左右,较 系统运行前底部 TP 浓度削减了 76\%, 达到国家地表水环境质量标准 II 类限值 $(0.025 \mathrm{mg} / \mathrm{L})$ 要求. 扬水曝气 系统对 TP 的抑制效果显著 $(r=-0.840, P<0.01)$ (图 6).

扬水曝气系统运行前, 黑河水库中、下部水体 $\mathrm{NH}_{4}^{+}-\mathrm{N}$ 浓度较大, 最大值为 $0.53 \mathrm{mg} / \mathrm{L}$; 随着扬水曝气系 统的持续运行, 底部水体 $\mathrm{NH}_{4}^{+}-\mathrm{N}$ 浓度逐步降低; 运行至第 $25 \mathrm{~d}$, 底部水体 $\mathrm{NH}_{4}^{+}-\mathrm{N}$ 浓度降至 $0.33 \mathrm{mg} / \mathrm{L}$, 垂向 水体 $\mathrm{NH}_{4}^{+}-\mathrm{N}$ 平均浓度为 $0.26 \mathrm{mg} / \mathrm{L}$; 运行 $40 \mathrm{~d}$ 后, 底部和垂向水体 $\mathrm{NH}_{4}^{+}-\mathrm{N}$ 浓度趋于均匀, 被平稳控制在 $0.23 \mathrm{mg} / \mathrm{L}$ 左右,较系统运行前底部水体 $\mathrm{NH}_{4}^{+}-\mathrm{N}$ 浓度削减了 $50 \%$, 达到国家地表水环境质量标准 II 类限值 $(0.5 \mathrm{mg} / \mathrm{L})$ 要求. 扬水曝气系统对 $\mathrm{NH}_{4}^{+}-\mathrm{N}$ 浓度的抑制效果显著 $(r=-0.941, P<0.01)$ (图 6$)$.

扬水曝气系统运行前, 黑河水库水体中 Fe 浓度最大值高达 $0.67 \mathrm{mg} / \mathrm{L}$, 超过国家地表水环境质量标准 II 类限值 $(0.3 \mathrm{mg} / \mathrm{L}) 1$ 倍以上; 在扬水曝气系统运行过程中, 中、下部水体的 $\mathrm{Fe}$ 浓度逐渐降低; 运行至第 $25 \mathrm{~d}$, 底部水体 $\mathrm{Fe}$ 浓度降至 $0.27 \mathrm{mg} / \mathrm{L}$, 垂向水体 $\mathrm{Fe}$ 平均浓度为 $0.18 \mathrm{mg} / \mathrm{L}$; 运行 $40 \mathrm{~d}$ 后, 底部水体 $\mathrm{Fe}$ 浓度 降至 $0.15 \mathrm{mg} / \mathrm{L}$, 垂向水体 $\mathrm{Fe}$ 平均浓度为 $0.14 \mathrm{mg} / \mathrm{L}$, 且上、下层水体 $\mathrm{Fe}$ 浓度趋于一致, 垂向平均削减率达 到 $86 \%$. 扬水曝气系统对 $\mathrm{Fe}$ 的抑制效果显著 $(r=-0.908, P<0.01$ ) (图 6).

黑河水库水体中 $\mathrm{TP} 、 \mathrm{NH}_{4}^{+}-\mathrm{N} 、 \mathrm{Fe}$ 浓度与扬水曝气系统运行时间之间均呈显著负相关 $(P<0.01)$, 相关系 
数 $\left(R^{2}\right)$ 分别达 $0.7054 、 0.8852$ 和 0.8249 (图 6).

扬水曝气系统运行前后, 黑河水库中锰浓度一直低于最低检测限值 $0.05 \mathrm{mg} / \mathrm{L}$.

$\mathrm{TP} /(\mathrm{mg} / \mathrm{L})$

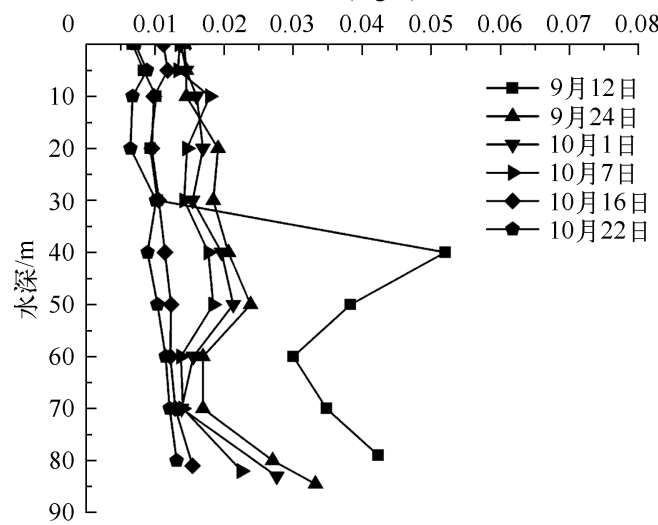

$\mathrm{Fe} /(\mathrm{mg} / \mathrm{L})$

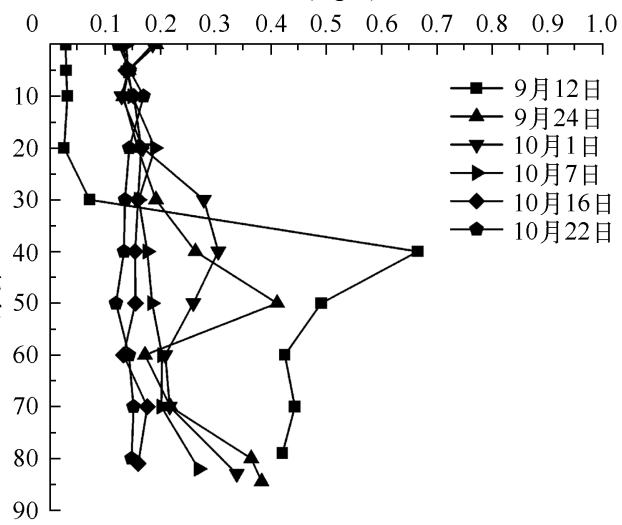

$\mathrm{NH}_{4}^{+}-\mathrm{N} /(\mathrm{mg} / \mathrm{L})$
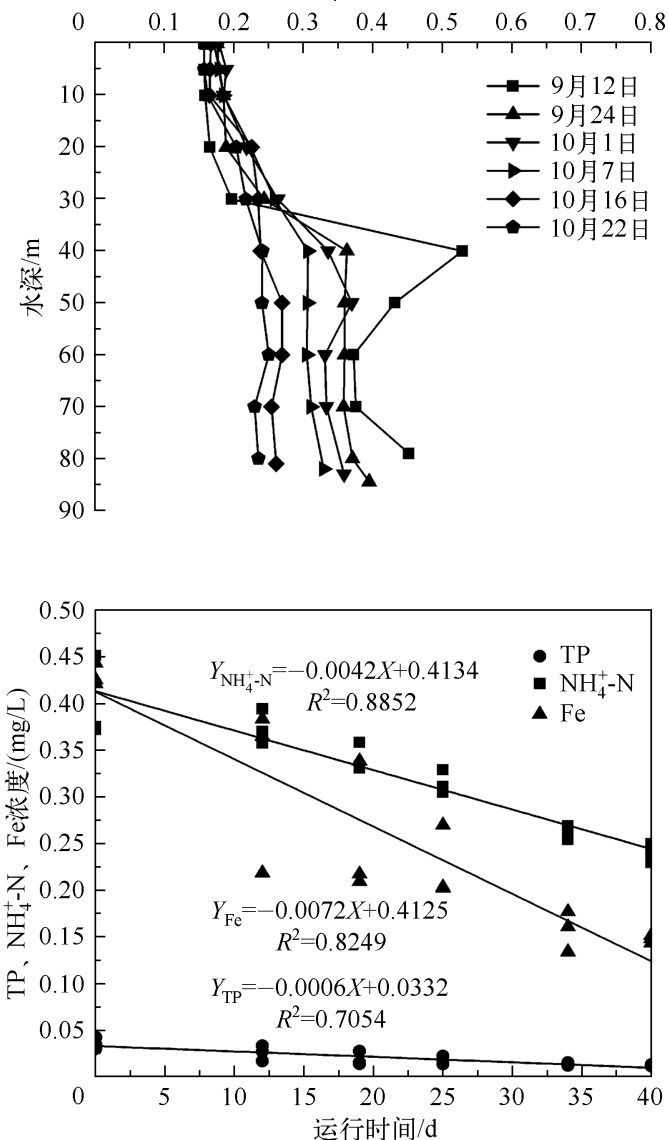

图 6 黑河水库 $\mathrm{S} 1$ 点位水体 $\mathrm{TP} 、 \mathrm{NH}_{4}^{+}-\mathrm{N}$ 和 $\mathrm{Fe}$ 浓度的垂向分布及相关性

Fig. 6 The vertical distribution and correlations of $\mathrm{TP}, \mathrm{NH}_{4}^{+}-\mathrm{N}$ and $\mathrm{Fe}$ concentrations in the water column of S1 site of Heihe Reservoir

2.7 .2 对藻类生长的抑制 黑河水库中藻类丰度与 Chl. a 浓度的变化趋势基本一致(图 7 ). 扬水曝气运行 前, 藻类丰度与 Chl. a 浓度最大值均出现在 $0 \sim 5 \mathrm{~m}$ 之间水体中, $5 \mathrm{~m}$ 以下水体中, 藻类丰度与 Chl. a 浓度随 着水深的增加而降低, 并逐渐趋于稳定, 符合中温带深水型水库藻类正常分布状态. 运行初期, $0 \sim 5 \mathrm{~m}$ 之间 水体的藻类丰度与 Chl. a 浓度不断减小, $10 \mathrm{~m}$ 以下水体的藻类丰度与 Chl. a 浓度相比运行前增加, 主要原因 是扬水曝气的充气混合作用将上部水体中的藻类输送到中、下部水体中;随着扬水曝气系统持续运行, 不断 被输送到下部水体的藻类光合作用受到抑制, 逐渐衰亡, 整个水体中藻类丰度不断降低. 扬水曝气系统对藻 类抑制效果显著 $(r=-0.835, P<0.01)$.

\section{3 结论}

对黑河水库全年水质的理化指标分析表明,黑河水库是一个底部季节性缺氧、高营养盐型水库, 水体整 体处于中-富营养状态. 全年水体呈单循环混合模式, 在 3-10 月形成热分层, 水体热分层导致水库水质的 分层.

水体分层限制了垂向水层间氧的传质交换, 加上水体和底泥的双重耗氧, 致使底部水体 DO 浓度锐减, 

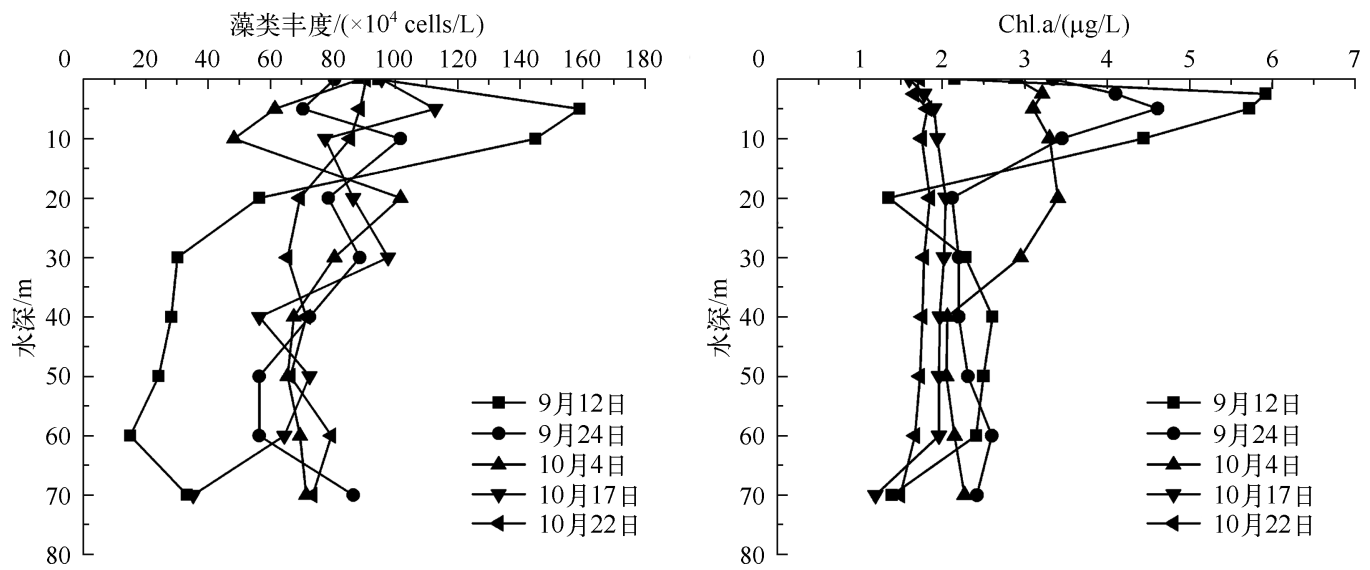

图 7 黑河水库 $\mathrm{S} 1$ 点位水体中藻类丰度及 Chl. a 浓度的垂向分布

Fig. 7 The vertical distribution of algae abundance and chlorophyll-a concentration in the water column of S1 site of Heihe Reservoir

造成沉积物中营养盐释放进人上覆水, 底层水体污染负荷大幅升高, 在水体自然混合期, 导致水库水质 污染.

黑河水库热分层末期,扬水曝气系统通过混合充氧增加水体 DO 浓度,增强垂向水体的流动性和交换 性,破坏水体分层,使水体提前混合,延长水质持续改善的作用时效.

扬水曝气系统的持续运行使水体底部 TP 浓度降至国家地表水环境质量标准 II 类限值以下; 水体底部 $\mathrm{NH}_{4}^{+}-\mathrm{N}$ 浓度由 $0.45 \mathrm{mg} / \mathrm{L}$ 降至 $0.23 \mathrm{mg} / \mathrm{L}$; 水体底部 $\mathrm{Fe}$ 浓度由 $0.42 \mathrm{mg} / \mathrm{L}$ 降至 $0.15 \mathrm{mg} / \mathrm{L}$; 水体底部镇浓度 低于最低检测限值 $(0.05 \mathrm{mg} / \mathrm{L})$; 水体上部 Chl. a 浓度由 $5.92 \mu \mathrm{g} / \mathrm{L}$ 降至 $1.66 \mu \mathrm{g} / \mathrm{L}$. 扬水曝气系统有效抑制 了底泥中污染物的释放,控制了藻类的生长繁殖,对黑河水质改善起到了至关重要的作用.

\section{4 参考文献}

[ 1 ] 韩博平. 中国水库生态学研究的回顾与展望. 湖泊科学,2010,22(2): 151-160. DOI 10. 18307/2010. 0201.

[2] 林国恩, 望 甜, 林秋奇等.广东流溪河水库湖沼学变量的时空动态特征. 湖泊科学, 2009, 21 (3) : 387-394. DOI 10. $18307 / 2009.0312$.

[ 3 ] Geller W. The temperature stratification and related characteristics of Chilean lakes in midsummer. Aquatic Sciences, $1992, \mathbf{5 4}(1)$ : 37-57.

[ 4 ] Lindenschmidt KE, Hamblin PF. Hypolimnetic aeration in Lake Tegel, Berlin. Water Research, 1997, 31 ( 7 ): 1619-1628.

[ 5 ] Imteaz MA, Asaeda T. Artificial mixing of lake water by bubble plume and effects of bubbling operation on algal bloom. Water Research, 2000, 34 (6) : 1919-1929.

[ 6 ] 孔海南. 应用扬水筒技术控制饮用水源水库富营养化的工程规模实验研究. 见: 中国环境科学学会水环境分会编. 2005 中国水环境污染控制与生态修复技术高级研讨会论文集. 宜昌: 中国环境科学学会水环境分会,2005:27-32.

[ 7 ] Clasen J. Raw water quality management at wahnbach reservoir. Water Supply, 2000, 18(1) : 581-585.

[ 8 ] Burris VL, Little JC. Bubble dynamics and oxygen transfer in a hypolimnetic aerator. Water Science Technology, 1998, 37 (2) :293-300.

[ 9 ] Visser PM, Ketelaars HAM, Mur LR. Reduced growth of the cyanobacterium Microcystis in an artificially mixed lake and reservoir. Water Science Technology, 1995, 32(4) :53-54.

[10] Simmons J. Algal control and destratification at Hanning-field reservoir. Water Science Technology, 1998, 37 (2): 309-316.

[11] Seo D, Jang DS, Kwon OH. The evaluation of effects of artificial circulation on Daechung Lake, Korea. Proceedings Vol. 
1 of 6th international Conference on the Conservation and Management of Lakes, 1995: 336-339.

[12] 刘 辉. 全流程生物氧化技术处理微污染原水. 北京: 化学工业出版社,2003.

[13] 丛海兵,黄廷林,廖晶广等. 水体修复装置一一扬水曝气器的开发. 中国给水排水,2005,21(3):41-45.

[14] 丛海兵,黄廷林,缪晶广等. 扬水曝气器的水质改善功能及提水、充氧性能研究. 环境工程学报, 2007,1(1):7-13.

[15] 王春雨,朱 俊,马 梅等. 西南峡谷型水库的季节性分层与水质的突发性恶化. 湖泊科学, 2005,17(1):54-60. DOI 10. 18307/2005.0109.

[16] 黄廷林,秦昌海,李 璇. 峡谷型水源水库的氮磷季节变化及其来源分析. 环境科学, 2013,34(9):3426-3428.

[17] 马 越. 北方河道型深水水库季节性分层的水质响应特征及其水质污染原位控制研究 [ 学位论文]. 西安: 西安建 筑科技大学, 2012 .

[18] 胡 平,刘 毅,唐忠敏等. 水库水温数值预测方法. 水利学报, 2010,41(9):1045-1053.

[19] 邓 云. 大型深水库的水温预测研究 [学位论文].成都:四川大学,2003.

[20] 李飞鹏, 张海平, 陈 玲. 小型封闭水体环境因子与叶绿素 a 的时空分布及相关性研究. 环境科学, 2013,34 (10): 3856-3860.

[21] 宋 策, 周孝德, 辛向文. 龙羊峡水库水温结构变化及其对下游河道水温的影响. 水科学进展, 2011, 22(3): $421-428$.

[22] 夏品华, 林 陶, 李存雄等. 贵州高原红枫湖水库季节性分层的水环境响应. 中国环境科学, 2011, 31 (9): 1477-1485.

[23]马 越,郭庆林, 黄廷林等. 西安黑河金盆水库季节性热分层的水质响应特征. 水利学报,2013,44(4):406-415.

[24] 黄廷林,柴蓓蓓. 水源水库水质污染与富营养化控制技术研究进展. 地球科学进展,2009,24(6):588-596.

[25] 黄廷林,章武首,柴蓓蓓. 大水深水库内源污染特征及控制技术. 环境污染与防治,2010,32(3):1-4.

[26] 国家环境保护总局《水和废水监测分析方法》编委会. 水和废水监测分析方法: 第 4 版. 北京: 中国环境科学出版 社, 2002 .

[27] Allen JI, Siddorn JR, Blackford JC et al. Turbulence as a control on the microbial loop in temperate seasonally stratified marine systems mode. Journal of Sea Research, 2004, 52(1): 1-20.

[28] Jamshidi S, Abu Bakar NB. Seasonal variations in temperature, salinity and density in the southern coastal waters of the Caspian Sea. Oceanology, 2012, 52(3) : 380-396.

[29] Boegman L, Loewen MR, Hamblin PF et al. Vertical mixing and weak stratification over zebra mussel colonies in western Lake Erie. Limnology and Oceanography, 2008, 53(3): 1093-1110.

[30] 何文杰. 安全饮用水保障技术. 北京:中国建筑工业出版社,2006.

[31］黄廷林,丛海兵,柴蓓蓓. 饮用水水源水质污染控制. 北京:中国建筑工业出版社,2009:128-164. 